\title{
Assessment of vibration amplitude and transmembrane pressure on vibratory shear enhanced membrane filtration for treating dairy wastewater
}

\author{
Sz. Gy. Szerencsés ${ }^{1}$, S. Beszédes ${ }^{1}$, Zs. László ${ }^{1}$, G. Veréb ${ }^{1}$, D. Szalay ${ }^{2}$,
} Zs. Hovorkáné Horváth ${ }^{3}$, C. Hodúr ${ }^{1,4}$, G. Rákhely ${ }^{4}$ and Sz. Kertész ${ }^{1 *}$

\footnotetext{
${ }^{1}$ Department of Process Engineering, Faculty of Engineering, University of Szeged, Moszkvai körút 9, H6725 Szeged, Hungary

${ }^{2}$ Faculty of Forestry, Institute of Forest and Environmental Techniques, University of Sopron, BajcsyZsilinszky út 4, H-9400 Sopron, Hungary

${ }^{3}$ Department of Technology, Faculty of Engineering, University of Szeged, Mars tér 7, H-6724 Szeged, Hungary

${ }^{4}$ Faculty of Science and Informatics, Institute of Environmental Science and Technology, University of Szeged, Közép fasor 52, H-6726 Szeged, Hungary
}

\section{ORIGINAL RESEARCH PAPER}

Received: April 29, $2020 \bullet$ Accepted: July 30, 2020

Published online: February 9, 2021

(C) 2020 The Author(s)

\section{ABSTRACT}

In this study, statistical analysis was performed to investigate the influence of operational parameters based on experimental results. The research aimed to know whether a long-term discontinuous module vibration operation is possible without adversely affecting filtration efficiency. Polymer membranes were compared by surface characteristics with contact angle measurements and selected for further membrane filtration experiments for dairy wastewater treatment. The effect of the main operational parameters, membrane module vibration amplitude $\left(A_{\text {vibr. }}\right)$ and transmembrane pressure $(T M P)$, was investigated using a vibratory shear enhanced processing (VSEP) module with ultrafiltration $(U F)$ and nanofiltration $(N F)$ membranes.

\footnotetext{
*Corresponding author. E-mail: kertesz@mk.u-szeged.hu
} 
Components of the permeates, including chemical oxygen demand (COD), were measured, and membrane rejections were calculated to compare with threshold limit values. The results suggest that proper combination of $A_{v i b r}$ and TMP could mitigate membrane fouling. However, discontinuous module vibration resulted in more clogged membrane with lower fluxes, but slightly higher rejections. We conclude that investigating the significance of operational parameters is necessary for a wider, more energy and environment-friendly application in wastewater treatment.

\section{KEYWORDS}

vibratory shear enhanced processing, dairy wastewater treatment, operational parameters analysis, ultrafiltration

\section{INTRODUCTION}

The high demand for milk has resulted in an enormous growth of dairy industry. In 2018, the world's total milk production was estimated more than 850 million tons according to International Dairy Federation (2019). Close to $2 \%$ of this amount turns into waste and without proper treatment this can be harmful for the environment. Although traditional treatments can be effective, these methods have many disadvantages, such as sludge formation and disposal problems, generation of greenhouse gases, or nutrients loss (Luo et al., 2012a).

Advanced techniques have emerged to purify polluted wastewaters for further industrial or domestic water consumption. In recent years, the consideration of specific separations came into focus. Membrane separation processes can be applied for wastewater treatment (Couto et al., 2018). Ultrafiltration $(U F)$ and nanofiltration $(N F)$ separation technologies, based on the concentration of macromolecules, have many industrial applications: from paint treatment to removal of microbes. $U F$ is a relatively novel process that can result in high-quality treatment at mild operating temperature using less energy and chemicals compared to other techniques. The importance of $U F$ membranes and systems is high: the market of $U F$ membranes have been continuously increasing since 1960, and it was estimated at USD 950 million in 2017. Since 1960, UF membranes and applications have been continuously improved in a wide variety of fields: food industry, wastewater reclamation, or juice concentration (Aani et al., 2020). Dairy sector is the largest pollutant within the food industry. One of the main reasons to use UF process in dairy industry is to recover proteins from the effluents with high protein rejection rates and high permeate fluxes (Luo et al., 2012a). However, modification and fabrication of $U F$ and NF membranes have a growing tendency, fouling is still the main problem of the wider application (Wang et al., 2019).

Work of Jaffrin (2012) showed high shear rate dynamic filtration technique promising for membrane fouling deduction, and other authors also confirmed the benefits of membrane module vibration in their work (Akoum et al., 2005; Frappart et al., 2008). There are several industrial vibratory shear enhanced processing (VSEP) installations in Europe, such as precious metal and polyethylene glycol recovery or biogas effluent treatment (Jaffrin, 2012). Membrane module vibration can produce high shear rate in fluids near the membrane surface, resulting from the deviation of membrane movement and liquid on the surface of the membrane by inertia (Takata and Tanida, 2018). Compared to conventional membrane separation processes, the vibratory shear enhanced system applies torsional vibration to increase separation intensity and reduce membrane fouling more effectively. It forces foulants to lift off and to get washed 
away from the surface of the membrane so that the concentration polarisation layer can be effectively reduced by vibration (Leong et al., 2016; Su et al., 2018). Luo and co-workers found that flux decline occurred in two ways during dairy effluent treatment by $N F$ at high shear rate (Luo et al., 2012b). The first flux decline was the adsorption fouling stage with low fouling rate, and the second stage of cake fouling with high fouling tendency. These results imply that the fouling mechanisms are greatly affected by shear rate. For this reason, the fouling mechanism at high shear rate needs to be further investigated.

Although the treatment of dairy effluents by shear-enhanced filtration systems has been investigated (Akoum et al., 2005; Frappart et al., 2008), tests for long-term discontinuous module vibration operation with different operational parameters have not been carried out yet. Also, the fouling mechanisms under high shear rate need to be clarified during ultrafiltration and nanofiltration of dairy wastewater. In this work, dairy wastewater treatment was investigated using a VSEP with UF and NF membranes. Membrane evaluation and selection started with contact angle measurements, followed by membrane filtration experiments in order to investigate the effects of operational parameters and compliance of the required wastewater discharged limits. Impact assessment of the main operational parameters, vibration amplitude, and transmembrane pressure $(T M P)$ were examined for permeate fluxes and membrane rejections, especially for chemical oxygen demand $(C O D)$ to know the purification efficiency of the technique.

\section{MATERIALS AND METHODS}

\subsection{Contact angle measurements}

A goniometer (DataPhysics, OCA 15 Pro type, Germany) with DataPhysics SCA software was used for contact angle measurements to know proper membrane character and to conduct membrane selection for further experiments. Measurements were carried out with dry, prewetted, and fouled membranes, dropping $5 \mu \mathrm{L}$ distilled water or dairy wastewater (with concentration of $5 \mathrm{~g} \mathrm{dm}^{-3}$ skimmed milk powder and $0.5 \mathrm{~g} \mathrm{dm}^{-3}$ detergent) on the surface of 8 different membranes (Table 1), diverse membrane material, pore size, or membrane weight cut-off (MWCO) and type. Every test was repeated 7 times and the averages of the results were calculated.

\subsection{Vibratory shear enhanced membrane separation tests}

Membrane separation experiments were carried out on VSEP device (New Logic Research Inc., USA) in laboratory mode with the earlier chosen membranes. In Fig. 1, the schematic VSEP experimental setup is shown.

Table 1. Membranes tested with contact angle measurements

\begin{tabular}{|c|c|c|c|c|c|c|c|c|}
\hline & & PES-10 & & & PES-5/ & & & \\
\hline Name & PES-30H & SYN & PES-6 & PES-5 SYN & TYVEK & PES-3 & NF-3 & NF-SR 3 \\
\hline Filtration & \multicolumn{6}{|c|}{$U F$} & \multicolumn{2}{|c|}{$N F$} \\
\hline Material & \multicolumn{6}{|c|}{ Polyethersulfone (PES) } & \multicolumn{2}{|c|}{$\begin{array}{c}\text { Thin film } \\
\text { composite (TFC) }\end{array}$} \\
\hline$M W C O$ & $30 \mathrm{kDa}$ & & $10 \mathrm{kD}$ & & $7 \mathrm{kDa}$ & $3 \mathrm{kDa}$ & $240 \mathrm{Da}$ & $200 \mathrm{Da}$ \\
\hline
\end{tabular}




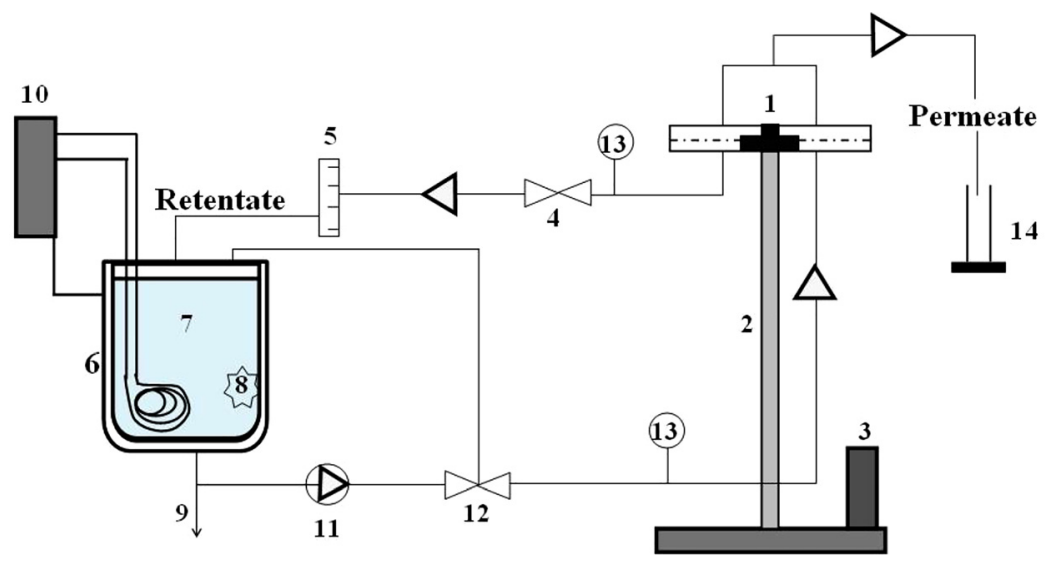

Fig. 1. Experimental setup: (1): membrane module; (2): torsion spring; (3): vibration eccentric motor; (4): valve 1; (5): flow meter; (6): thermostated feed tank; (7): wastewater; (8): thermometer; (9): bibcock; (10): thermostated puffer tank; (11): feed pump; (12): valve 2; (13): pressure transducers; (14): permeate collection

To examine the effects and assessment of the main operational parameters on efficiency, membrane module vibration amplitude $\left(A_{\text {vibr. }}\right)$ and TMP values were changed gradually during measurements. In order to investigate the possibility of a discontinuous module vibration operation, instead of continuous vibration mode the membrane filtration experiments order was the following: At the beginning of the experiments the $A_{v i b r}$. was set to maximum $(0.0250 \mathrm{~m})$, then adjusted to an intermediate value $(0.0125 \mathrm{~m})$, then switched off for non-vibration mode, after it was turned back to the intermediate, and finally to the maximum value. At each given amplitude TMP values were set first to $0.4 \mathrm{MPa}$, then $0.6,0.8$, and $1.0 \mathrm{MPa}$ with $U F$ and to 2.0, then 2.5, 3.0, and $3.5 \mathrm{MPa}$ with NF membrane (Table 2 and Fig. 3). The analysis of the measurement data was performed with the Statistica 13.0 program, using the analysis of variance method. Between the adjusted operational parameters, permeate fluxes were measured and samples were collected and analysed for organic content membrane rejection calculations ( $R \%)$, using the following Eq. (1):

$$
R_{\%}=1-\frac{c_{\text {perm COD }}}{c_{\text {feed COD }}} \times 100[\%]
$$

\section{RESULTS AND DISCUSSIONS}

\subsection{Membrane surface characterisations by contact angle measurements}

Contact angle measurements were carried out on 8 tested membranes by dropping exact amount of the distilled water or dairy wastewater sample on the membrane surface. It was observed that contact angle values were more affected by the type of the dropped sample and the membrane status, both wet and dry interaction, than the individual membrane characteristics, such as $M W C O$. Contact angle values varied between $32^{\circ}$ and $58^{\circ}$ on $U F$ membranes and $0^{\circ}$ and $31^{\circ}$ on 
Table 2. Order of gradually changed operational parameters during membrane filtrations

\begin{tabular}{|c|c|c|c|c|c|c|c|c|c|c|c|c|c|c|c|c|c|c|c|c|c|}
\hline \multirow{3}{*}{$\begin{array}{l}\text { Filtration } \\
U F\end{array}$} & \multirow{3}{*}{$\begin{array}{c}\text { Parameter } \\
\text { Amplitude }[\mathrm{m}] \\
T M P[\mathrm{MPa}]\end{array}$} & \multicolumn{20}{|c|}{ Operating values } \\
\hline & & \multicolumn{4}{|c|}{0.0250} & \multicolumn{4}{|c|}{0.0125} & \multicolumn{4}{|l|}{0.0} & \multicolumn{4}{|c|}{0.0125} & \multicolumn{4}{|c|}{0.0250} \\
\hline & & 0.4 & 0.6 & 0.8 & 1.0 & 0.4 & 0.6 & 0.8 & 1.0 & 0.4 & 0.6 & 0.8 & 1.0 & 0.4 & 0.6 & 0.8 & 1.0 & 0.4 & 0.6 & 0.8 & 1.0 \\
\hline$N F$ & $T M P[\mathrm{MPa}]$ & 2.0 & 2.5 & 3.0 & 3.5 & 2.0 & 2.5 & 3.0 & 3.5 & 2.0 & 2.5 & 3.0 & 3.5 & 2.0 & 2.5 & 3.0 & 3.5 & 2.0 & 2.5 & 3.0 & 3.5 \\
\hline
\end{tabular}




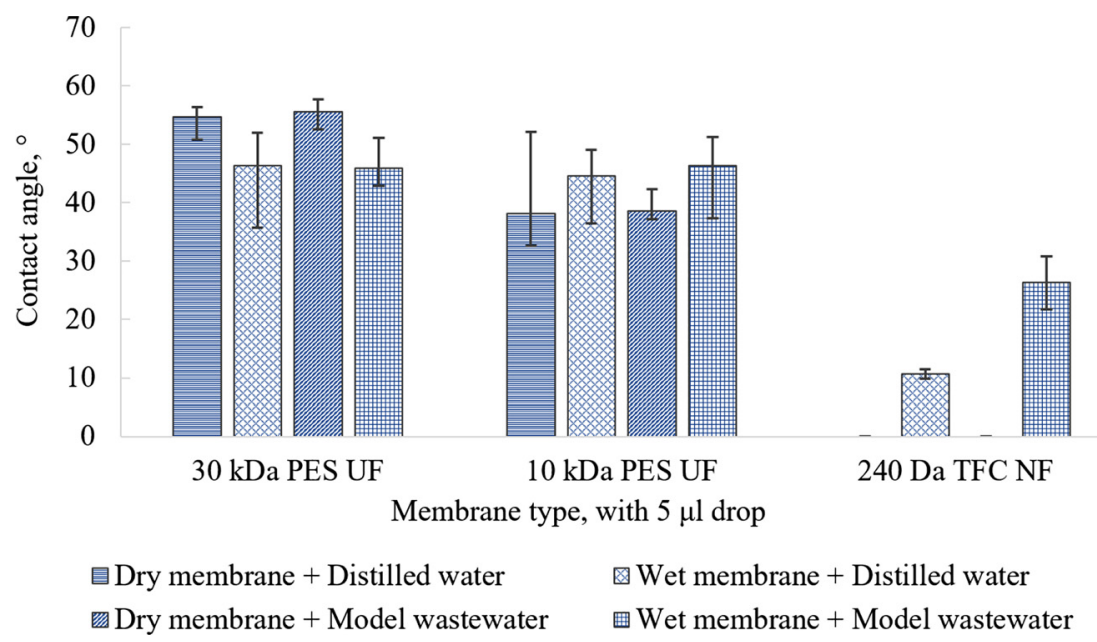

Fig. 2. Measured contact angle values on the selected membranes

$N F$ membranes, which means that membrane surface was rather hydrophilic $\left(<90^{\circ}\right)$ and $N F$ membrane had a highly hydrophilic membrane surface attribute. On the contrary, the highest $M W C O 30 \mathrm{kDa}$ PES ultrafiltration membrane appeared to be the least hydrophilic membrane with the highest measured values out of the tested membranes (Fig. 2). Based on the results, 3 membranes were selected. $240 \mathrm{Da}$ TFC NF as the most hydrophilic one, because high membrane water affinity with aqueous wastewater may result higher membrane permeability, and $10 \mathrm{kDa}$ PES UF membrane, which was the most stable under all experimental conditions. Although $30 \mathrm{kDa} P E S$ UF membrane was the least hydrophilic and had the highest $M W C O$, it was chosen to test the compliance of permeate organic content for effluent standard limits. Also, typically the $10 \mathrm{kDa}$ is the whey ultrafiltration $M W C O$ in dairy industry, and $30 \mathrm{kDa}$ is often used to separate whey proteins effectively (Wen-Qiong et al., 2019). These three selected membranes were subjects to filtration testing to obtain a wide range of results for membrane separation efficiency.

\subsection{Impact assessment of operational parameters in VSEP membrane filtration}

Fluxes are comparable, if the values are calculated per transmembrane unit pressure, namely the permeability, with the unit of $1 \mathrm{~m}^{-2} \mathrm{~h}^{-1} \mathrm{MPa}^{-1}$. In this case, the maximum fluxes were $160 \mathrm{~lm}^{-2} \mathrm{~h}^{-1} \mathrm{MPa}^{-1}$ with $30 \mathrm{kDa}$ PES UF, $1101 \mathrm{~m}^{-2} \mathrm{~h}^{-1} \mathrm{MPa}^{-1}$ with $10 \mathrm{kDa}$ PES UF, and $40 \mathrm{~lm}^{-2} \mathrm{~h}^{-1} \mathrm{MPa}^{-1}$ with $240 \mathrm{Da}$ TFC NF membranes. In this comparison, flux values correspond as expected to the $M W C O$ values of the membranes (Fig. 3).

With $30 \mathrm{kDa} P E S$ UF and $240 \mathrm{Da}$ TFC NF higher maximum flux rise was achieved by vibration, while with $10 \mathrm{kDa} P E S U F$, higher maximum permeate flux was achieved by TMP increment from minimum to maximum at the same vibration. Analysis of variance was used for the results of the experiments, based on mean values with a confidence interval of $95 \%$ confidence level. Results are presented for $U F$, and the impact of TMP on permeate fluxes was significant. As a generally expected trend, fluxes increased proportionally as the transmembrane 

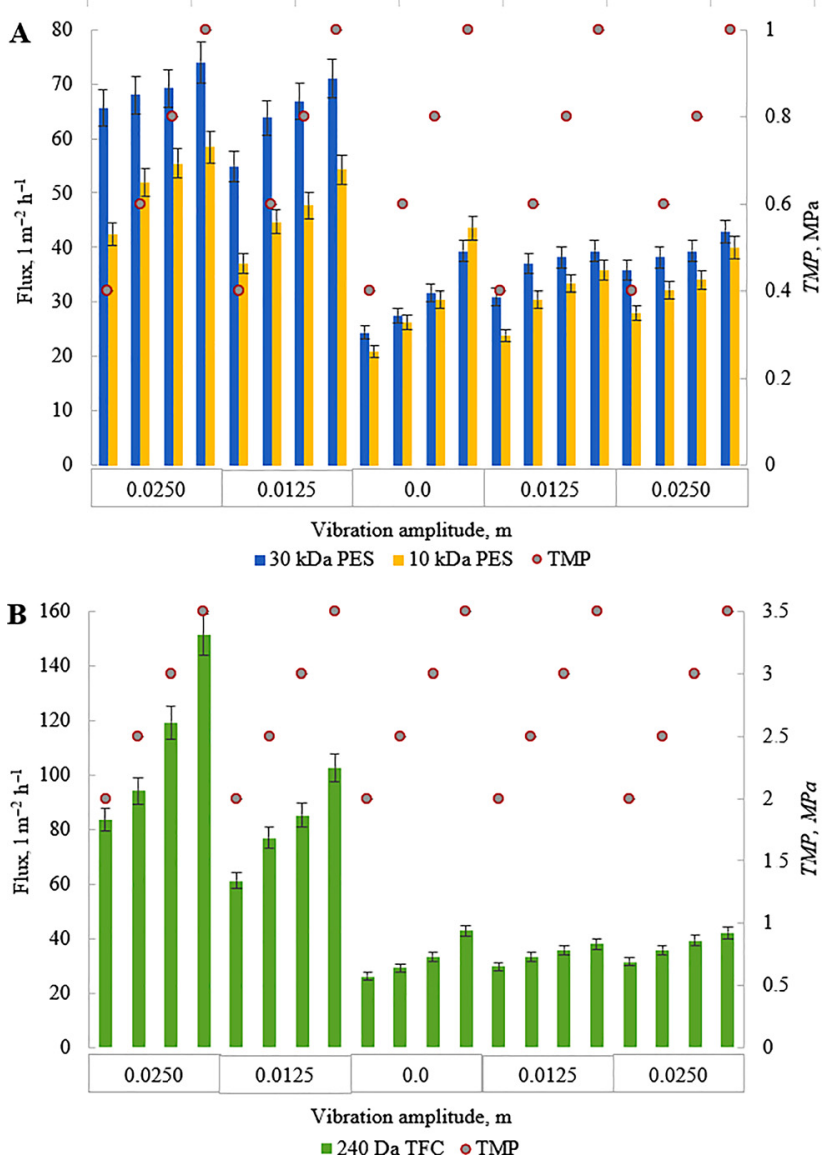

Fig. 3. Permeate fluxes with $U F(\mathrm{~A})$ and $N F(\mathrm{~B})$ membranes plotted as a function of membrane module vibration amplitude $\left(A_{\text {vibr. }}\right)$ and transmembrane pressure $(T M P)\left(\mathrm{q}_{\mathrm{Vrec}}=0.9085 \mathrm{~m}^{3} \mathrm{~h}^{-1} ; \mathrm{T}=25.5 \pm 1.5^{\circ} \mathrm{C}\right)$

pressure increased. Figure 4 shows that on each vibration amplitude level the same amount of TMP increment, $0.6 \mathrm{MPa}$ (from $0.4 \mathrm{MPa}$ to $1.0 \mathrm{MPa}$ ) with $U F$ and $1.5 \mathrm{MPa}$ (from $2.0 \mathrm{MPa}$ to 3.5 MPa) with $N F$, could enhance the fluxes dissimilarly. In the case of UF membranes (Fig. 4A) TMP could increase fluxes the most without applied vibration, at higher vibration amplitudes the flux-enhancing effect of transmembrane pressure was less notable. With NF membrane (Fig. 4B) it was a different tendency, flux increment decreased almost continuously, mostly due to the skin-type structure of the membrane.

In case of the average fluxes measured without vibration are considered $100 \%$, the maximum $A_{\text {vibr. }}(0.025 \mathrm{~m})$ could increase the fluxes $125.2 \%$ with $30 \mathrm{kDa} P E S U F, 71.9 \%$ with $10 \mathrm{kDa} P E S$ $U F$, and $240.5 \%$ with $240 \mathrm{Da}$ TFC NF. Maximum flux rise caused by TMP change with $30 \mathrm{kDa}$ PES UF and 240 Da TFC NF was lower than the flux increment achieved by vibration by two and three times, respectively. In contrast, with $10 \mathrm{kDa} P E S U F$ higher maximum permeate flux was achieved by TMP change, but only half times the value resulted by vibration. 
Change in permeate flux is calculated from the flux data measured at the lowest

A (0.4 MPa) to the highest (1.0 MPa) TMP at the same vibration amplitude level.

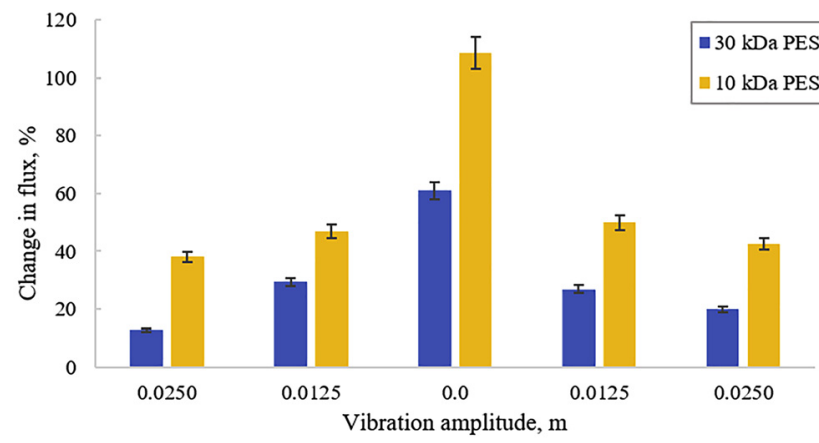

B Change in permeate flux is calculated from the flux data measured at the lowest B (2.0 MPa) to the highest (3.5 MPa) $T M P$ at the same vibration amplitude level.

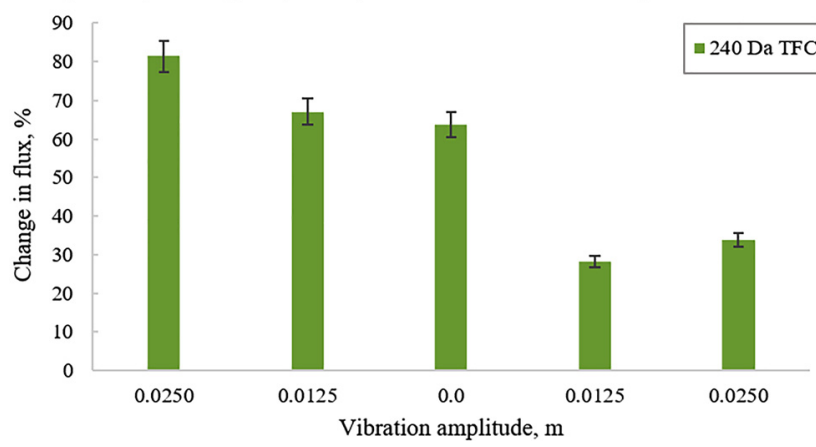

Fig. 4. Effect of transmembrane pressure (TMP) increment on permeate fluxes with $U F(\mathrm{~A})$ and $N F(\mathrm{~B})$

The effect of vibration on fluxes was clearly significant (Fig. 5). For $U F$, analysis of variance was used to investigate the impacts. The module vibration's membrane fouling mitigation effect was obvious, as, before the period without vibration $\left(A_{\text {vibr. }}=0\right)$, fluxes were much higher, the strong significant difference is visible, i.e., it helps maintaining membrane pore permeability. To know whether a discontinuous operational mode or inserted period is possible and useful for the operation, the vibration was turned back after the non-vibrational part. This way, the highest flux increment was reached with $30 \mathrm{kDa} P E S$ UF. Fluxes could increase to $18.4 \%$ in the intermediate $A_{v i b r}$. period and with $27.2 \%$ in the maximum $A_{v i b r}$. period, but statistically this growth is not significant.

\subsection{Compliance of threshold limits and membrane rejections}

Measurements were made and rejection values were calculated for $C O D$, turbidity, total dissolved solids (TDS), salts, and milk components. These were rejected in almost $100 \%$ by $240 \mathrm{Da}$ TFC NF membrane that could help re-use waters in the dairy industry. Statutory requirements highly focus on $C O D$, as it is an indicator for potential highly harmful attribute of the wastewaters, therefore we analysed this in detail. The initial value for organic matter content of the model dairy wastewater was $4,900 \mathrm{mg} \mathrm{L}^{-1}$. To comply with the official emission limits (National 


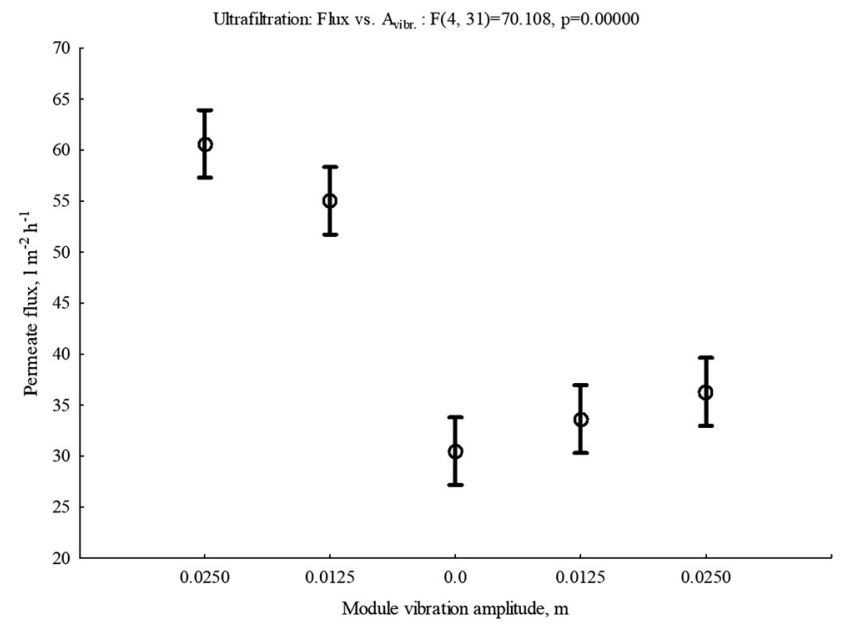

Fig. 5. Analysis of variance: Effect of module vibration amplitude on permeate fluxes with UF membranes (mean values with a confidence interval of $95 \%$ confidence level)

Legal Acts, Hungary), $110 \mathrm{mg} \mathrm{L}^{-1}$ for living and $1,200 \mathrm{mg} \mathrm{L}^{-1}$ for sewer waters, the rejections for the initial $C O D$ value need to reach at least 97.7 and $74.5 \%$, respectively (Fig. 6). In the case of $N F$, this means that in one-step filtration a lower level was reached than the discharge limit for living waters.

To understand the influence of the operational parameters on $C O D$ membrane rejection, analysis of variance was used, and results for UF are represented in Fig. 7. Regarding TMP, as operating pressure increased, rejection followed the trend until a critical pressure value, around $0.8 \mathrm{MPa}$, that was related to the highest $C O D$ rejection (Fig. 7A). This data shows clearly how properly set operational parameters can affect the efficiency of filtration and result in more environment-friendly operation. In the case of vibration, maximum and medium vibration amplitudes resulted in close similar rejection values as the non-vibrational phase (Fig. 7B). On
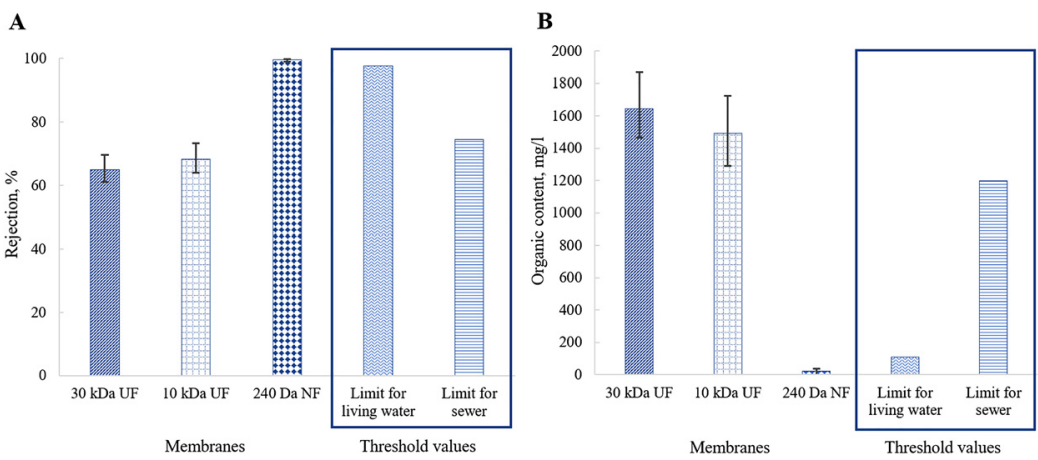

Fig. 6. Organic content mean values of permeates (A) and calculated rejections (B). In the frame: threshold limits and calculated rejections (National Legal Acts, Hungary) 
A

Ultrafiltration: $C O D$ rejection vs. $T M P: F(3,31)=12.814$,

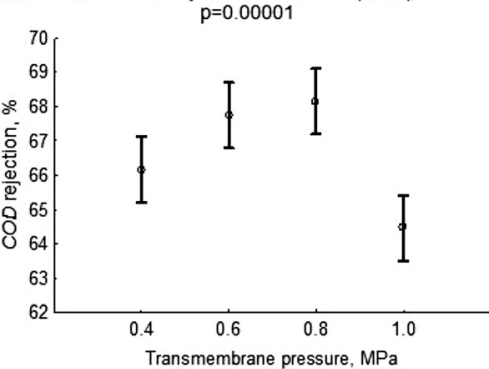

B

Ultrafiltration: $C O D$ rejection vs. $A_{\text {vibr. }}: F(4,31)=8.4557$,

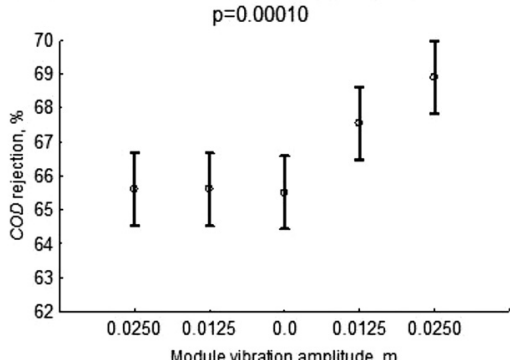

Fig. 7. Analysis of variance: Effect of transmembrane pressure (A) and module vibration amplitude (B) on COD rejection with UF membranes (mean values with a confidence interval of $95 \%$ confidence level)

the contrary, rejection values significantly increased as the vibration was turned back after the zero-meter amplitude period that suggests the concentration polarisation layer was changed remarkably by vibration.

Specific energy demand $\left[\mathrm{kWh} \mathrm{m}^{-3}\right]$ calculations revealed that applied vibration, both maximum $\left(A_{\text {vibr. }}=0.0250 \mathrm{~m}\right)$ and intermediate $\left(A_{\text {vibr. }}=0.0125 \mathrm{~m}\right)$, resulted in cc. $50 \%$ lower energy consumption related to the unit of permeate. This data shows how effectively vibration creates more filtrate, by the reduction of clogging on the membrane surface. Zsirai et al. (2016) concluded that the energy demand of mechanically imposed shear in membrane processes becomes more energy efficient in terms of $\mathrm{kWh} \mathrm{m}^{-3}$ permeate at lower shear rates.

\section{CONCLUSIONS}

Our results show that contact angle values were more affected by the type of the dropped liquid and the membrane status interaction and only secondarily by the specific membrane characteristics.

At main operational parameters with $U F$ membranes TMP could increase fluxes the most without applied vibration, at higher vibration amplitudes the flux-enhancing effect was less notable. With NF, the TMP induced flux-rise at a given amplitude decreased almost continuously, presumably to the different structure of the NF membrane.

Module vibration in both UF and NF caused higher fluxes, thus less flux decline and slightly improved membrane rejections. Vibration could increase permeate fluxes after a non-vibrational period, that might be useful for industrial, long-term applications, although significantly higher rejection results were observed. On NF membrane with intermediate vibration one and a half times, with the maximum vibration two and a half times flux increment was reached. In the future further experiments are needed to clarify the effect of intermittent membrane module vibration based on specific energy demand.

NF membrane rejected all measured values in almost 100\% that could help re-use waters and different types of wastewater in food industry. For UF membranes, impact assessment showed that a critical pressure value can be evaluated, to help properly set operational parameters. Our study reveals the significance of the operational parameters along with their prospective wider 
applications in wastewater treatment. It can affect the efficiency of the membrane filtration and that results in more energy and environment-friendly operation.

\section{ACKNOWLEDGEMENT}

Supported by the ÚNKP-19-2 New National Excellence Program of the Ministry for Innovation and Technology. The authors are grateful for the financial support of the Hungarian Science and Research Foundation (OTKA contract number K 115691), the Hungarian State and the European Union (EFOP-3.6.2-16-2017-00010). Sz. K. thanks the support of the János Bolyai Research Scholarship of the Hungarian Academy of Sciences and the New National Excellence Program of the Ministry of Human Capacities (BO/00576/20/4 and UNKP-20-5-SZTE-384).

\section{REFERENCES}

Aani, S.A., Mustafa, T.N., and Hilal, N. (2020). Ultrafiltration membranes for wastewater and water process engineering: a comprehensive statistical review over the past decade. Journal of Water Process Engineering, 35: 101241.

Akoum, O., Jaffrin, M.Y., and Ding, L.H. (2005). Concentration of total milk proteins by high shear ultrafiltration in a vibrating membrane module. Journal of Membrane Science, 247: 211-220.

Couto, C.F., Lange, L.C., and Amaral, M.C.S. (2018). A critical review on membrane separation processes applied to remove pharmaceutically active compounds from water and wastewater. Journal of Water Process Engineering, 26: 156-175.

Frappart, M., Jaffrin, M.Y., Ding, L.H., and Espina, V. (2008). Effect of vibration frequency and membrane shear rate on nanofiltration of diluted milk, using a dynamic filtration system. Separation and Purification Technology, 62: 212-221.

IDF (2019). International dairy federation, the world dairy situation. In: ESADA Congress, 2019, Available at: https://agriprofocus.com/upload/post/CAROLINE-EMOND-min_(1)1573130127.pdf (Accessed 28 April 2020).

Jaffrin, M.Y. (2012). Dynamic filtration with rotating disks and rotating and vibrating membranes: an update. Current Opinion in Chemical Engineering, 1: 171-177.

Leong, J., Tan, J., Heitz, A., and Ladewig, B.P. (2016). Use of vibratory shear enhanced processing to treat magnetic ion exchange concentrate: a techno-economic analysis. Desalination, 383: 46-52.

Luo, J., Cao, W., Ding, L.H., Zhu, Z., Wan, Y., and Jaffrin, M.Y. (2012a). Treatment of dairy effluent by shear-enhanced membrane filtration: the role of foulants. Separation and Purification Technology, 96: 194-203.

Luo, J., Ding, L., Wan, Y., Paullier, P., and Jaffrin, M.Y. (2012b). Fouling behavior of dairy wastewater treatment by nanofiltration under shear-enhanced extreme hydraulic conditions. Separation and $\mathrm{Pu}$ rification Technology, 88: 79-86.

$\mathrm{Su}, \mathrm{X}$., Li, W., Palazzolo, A., and Ahmed, S. (2018). Concentration polarization and permeate flux variation in a vibration enhanced reverse osmosis membrane module. Desalination, 433: 75-88. 
Takata, K. and Tanida, K. (2018). Structure of shear-enhanced flow on membrane surface with horizontal vibration and its effect on filtration performance. Chemical Engineering Research and Design, 134: 130139.

Wen-Qiong, W., Yun-Chao, W., Xiao-Feng, Z., Rui-Xia, G., and Mao-Lin, L. (2019). Whey protein membrane processing methods and membrane fouling mechanism analysis. Food Chemistry, 134: 130139.

Wang, W.Q., Wa, Y.C., Zhang, X.F, Gu, R.X., and Lu, M.L. (2019). Whey protein membrane processing methods and membrane fouling mechanism analysis. Food Chemistry, 289: 468-481.

Zsirai, T., Qiblawey, H., A-Marri, M.J., and Judd, S. (2016). The impact of mechanical shear on membrane flux and energy demand. Journal of Membrane Science, 516: 56-63.

28/2004. (XII. 25.) National Legal Acts, Hungary for living water, in Hungarian. Available at: https://net. jogtar.hu/jogszabaly?docid=a0400028.kvv (Accessed 28 April 2020).

204/2001. (X. 26.) National Legal Acts, Hungary for sewer, in Hungarian. Available at: https://net.jogtar.hu/ jogszabaly?docid=A0100204.KOR\&txtreferer=99500057.TV (Accessed 28 April 2020).

Open Access. This is an open-access article distributed under the terms of the Creative Commons Attribution 4.0 International License (https://creativecommons.org/licenses/by/4.0/), which permits unrestricted use, distribution, and reproduction. in any medium, provided the original author and source are credited, a link to the CC License is provided, and changes - if any - are indicated. (SID_1) 